\title{
llinca llian
}

\section{La(s) figura(s) de Pablo Neruda construida(s) en la cultura rumana de la segunda etapa del régimen comunista rumano (1965-1989)}

Desde el momento en que Neruda irrumpió en el escenario cultural rumano, en 1947, con la traducción de «Los muertos de la plaza» hecha por Petre Solomon, su nombre asociado tanto al poeta como al activo ciudadano "progresista» no dejó de repetirse y de cobrar cada vez mayor sonoridad en las páginas de las revistas culturales y los oficiosos comunistas. Convertido en la propia encarnación del poeta militante, considerado un ejemplo de escritor comprometido con la causa del socialismo mundial, promovido además como un "gran amigo de Rumania», gracias a la traducción de la antología 44 poetas rumanos publicada en 1967 en Buenos Aires, Neruda obtuvo en la Rumania de las primeras dos décadas del régimen comunista una fama incomparablemente más alta que la de cualquier otro escritor de Latinoamérica. El público rumano no solo estuvo alimentado constantemente con las producciones líricas del gran poeta, que, entre otras, gozaba de los favores de los dirigentes culturales de la URSS y, en consecuencia, de sus serviles homólogos rumanos. También los vaivenes de la asombrosa vida del poeta chileno -su persecución por el dictador González Videla, su largo viaje por los países europeos y asiáticos socialistas entre 1950 y 1952, su vuelta a Chile después del exilio, su fugaz encarcelamiento en Argentina en 1957 o sus participaciones en el Congreso Mundial de la Paz- se comentan en detalle y suscitan alternamente indignación o loas. También sus opiniones cívicas -ya sea que se trate de la represión de la revolución de Hungría de 1956, presentada como unas saludables «acciones liberadoras» del ejército soviético, o de la Alianza para el Progreso, vista como una hipócrita intervención imperialista- se difunden puntualmente en la prensa cultural rumana hasta 1964, donde la figura de Neruda es erigida en el símbolo del más confiable «compañero de ruta» de los forjadores del comunismo mundial. No solo numerosas notas y artículos exaltan su recepción del Premio Stalin de la Paz en 1953 y su entrega, de manos de Ilya Ehrenburg, en 1954, sino que incluso unos actos culturales circunstanciales, organizados en su honor en Moscú, Santiago de Chile o en otras ciudades, retienen la atención de la prensa que, asimismo, informa consecuentemente sobre la aparición de sus nuevas obras y reseña los reconocimientos 
variados de los que el poeta se hace acreedor ${ }^{1}$. En tres años sucesivos (1949, 1950, 1951) aparecen tres tomos de poesía antifascista de Neruda ${ }^{2}$, en 1956 se publica, en la excelente traducción de Maria Banuş, Las uvas y el viento (1954), para que, nueve años más tarde, en 1963, la misma traductora se encargue de elaborar una antología titulada da sugestivamente Poezii noi (Poesías nuevas, escogidas del ciclo de las Odas, Estravagario y Navegaciones y regresos). Todos estos libros reciben numerosas y (a veces) atentas reseñas, que contribuyen pues a darle a Neruda una visibilidad incomparable en la cultura rumana.

En un trabajo previo que se dedicó a ofrecer una «lectura distante» de la recepción de la poesía latinoamericana en la Rumania socialista (Ilian y Ţiţei, en prensa) llegamos a probar en términos cuantitativos la preeminencia incontestable de Neruda entre los poetas latinoamericanos traducidos al rumano hasta 1964. Lo que se desprendió nítidamente de este prolijo análisis fue el hecho de que en las primeras dos décadas del comunismo rumano, la imagen que se le construye al poeta evoluciona junto a las transformaciones que tienen lugar en el escenario cultural rumano, el cual retiene de la producción in fieri del poeta, entre 1947 y 1973, los aspectos que mejor responden a los rasgos dominantes de sus políticas culturales. Así, en una primera etapa (19441953), denominada por Eugen Negrici «estalinismo integral» (2019), Neruda aparece como la encarnación más ejemplar del comunista militante, aureolado por su heroica participación en la guerra civil española, y su poesía está empleada como mero instrumento propagandístico. Así, su contenido efectivo desaparece tras el invariable «mensaje» ideológico, prefijado por los dirigentes de las políticas culturales encaminadas a promover la línea ortodoxa del realismo socialista. De aquí la poca atención dada al grado de calidad (o al menos de corrección) de las traducciones, que en esta primera etapa suelen ser más bien deficientes.

Su imagen de poeta «ortodoxo» queda poco alterada también en una segunda etapa, iniciada tras la muerte de Stalin, cuando el campo cultural rumano se escinde entre los dogmáticos realistas socialistas (entre ellos, en una posición central, Eugen Jebeleanu y Mihai Beniuc) y los «modernos» agrupados especialmente alrededor de la revista Steaua de Cluj que iban a conseguir finalmente a imprimir una nueva orientación a la

1 Para dar solo unas muestras: en la prensa de 1949 aparecen nada menos que seis artículos de inflamado elogio, seis notas varias sobre sus declaraciones y andanzas, catorce fragmentos de poemas publicados en 16 números de diversas revistas y dos artículos políticos de Neruda. En 1951, cuando Neruda llega por segunda vez a Bucarest, su discurso pronunciado ante sus anfitriones de la Unión de Escritores de Rumania, se publica íntegramente en dos publicaciones y abreviado en otras tres, junto a unas dos entrevistas, seis artículos de presentación elogiosa y diez traducciones de poemas publicadas en siete publicaciones. Los datos son sintetizados de nuestra bibliografía exhaustiva de la recepción de la literatura latinoamericana en la Rumania socialista (Ilian, in fieri). Precisamente por la existencia de esta bibliografía y por razones de espacio, prescindiremos en este trabajo de indicar cada una de las entradas bibliográficas (traducciones, reseñas, artículos, notas, entrevistas, etc.) y solo daremos aquí la traducción al español de los fragmentos citados, sin el texto original.

2 Ver Libros de Neruda publicados en rumano hasta 1989, en la Bibliografía. 
cultura rumana, ubicándola bajo el signo de la autonomía de lo estético (ver Ilian, en prensa; Ilian y Țiţei, en prensa). La confiscación de la poesía de Neruda por unos gatekeepers $^{3}$ que se escogen de los más rancios y dogmáticos realistas socialistas (Mihnea Gheorghiu, Eugen Jebeleanu, Mihai Beniuc) hace que, a pesar del número impresionante de poemas traducidos, noticias y artículos encomiásticos (o, mejor dicho, justo por causa de esta abundancia), el nombre de Neruda quede asociado al frente «reaccionario» del campo cultural, mientras que el poeta latinoamericano que encarna el ideal lírico para el grupo de Steaua es César Vallejo. De hecho, el director de esta revista, A. E. Baconsky declara en varias ocasiones que el poeta peruano es uno de sus favoritos.

En 1964 -cuando Gheorghiu-Dej lee en la plenaria del Comité Central del Partido Obrero Rumano (PMR) la Declaración de la posición de su partido con respecto a los movimientos socialistas internacionales, que prácticamente es una declaración de independencia de la tutela soviética- se considera en las historias literarias rumanas que arranca el «deshielo cultural», o lo que es lo mismo que una visible atenuación de la presión ideológica en la cultura. Nos proponemos en este espacio estudiar la recepción de Neruda a partir de este año, hasta 1989, porque creemos interesante estudiar cómo evoluciona la figura de Neruda en el escenario cultural rumano de esta etapa. En otras palabras, nos interesa estudiar cómo se desenvuelve el destino de un poeta que entre 1947 y 1964 había sido convertido en una de las figuras más insignes de la literatura latinoamericana mundial «comunista» (Locane, 2021) y también en el principal aliado político-ideológico de los dirigentes del campo cultural rumano. Pretendemos entender qué pasa con este poeta a partir del momento en que el clima cultural en su conjunto se transforma y la vehemencia militante de las primeras dos décadas no solo se mitiga, pero incluso se ve -al menos por unos años- como de mal gusto. Dividiremos nuestro trabajo en dos partes, tomando como referencia el año 1971, cuando Ceauşes$\mathrm{cu}$, en un infausto discurso conocido como las «Tesis de julio» pretende reorientar la cultura rumana hacia un dogmatismo esta vez de tipo nacionalista en que pueda prosperar el culto a la personalidad.

\section{4-1971}

Eugen Negrici, uno de los historiadores más prominentes de la literatura rumana del período comunista, sugiere que la cultura rumana a partir de 1964 se debería comprender ante todo como «un proceso de reconquista [en español en original] que recuperó, recurriendo a los recursos literarios clásicos, el terreno perdido por la literatura» (2019, 270; cursivas en original), o sea de «la literatura como tal (la de la autonomía de

3 Empleamos el término de gatekeeper, que se refiere a la red de editores, traductores, agentes, etc. que contribuyen a hacer conocer a cierto(s) autor(es) en determinado(s) espacio(s) cultural(es), en la acepción acuñada por Marling (2016). 
lo estético)» (268). Se da en estos años, según Negrici, una urgencia de «recuperar el tiempo malgastado durante el gran extravío realista socialista» (264) y el impulso fundamental de los artistas e intelectuales es «el desahogo [...] incluso de revancha» (270). No se trata para nada de una liberación total de las coerciones ideológicas, pues eso sería imposible dentro de un régimen totalitario. En cambio, lo que tiene lugar es una vuelta a la tradición de la cultura rumana de guiarse por las tendencias presentes en las grandes culturas occidentales y de sincronizarse con el pulso intelectual de las metrópolis europeas, donde -en lo que toca a la recepción de la literatura latinoamericanaestaba forjándose en estos años el impetuoso fenómeno del boom, por lo cual también Rumania empieza a penetrar cada vez con mayor fuerza la literatura latinoamericana mundial de tipo «capitalista» (Locane, 2021, 194). En este contexto, es explicable por qué las figuras centrales de la «literatura mundial comunista» y especialmente los poetas -Pablo Neruda, Raúl González Tunón y Nicolás Guillén entre otros- pierden bastante terreno ante el deslumbramiento que produce la prosa del subcontinente latinoamericano a partir de los años sesenta en Occidente y, desde allí, en todo el mundo.

Efectivamente, desde 1965, en comparación con la abundancia impresionante de textos dedicados a él en las primeras dos décadas del régimen comunista, hay cada vez menos noticias sobre Neruda en la prensa rumana. Con todo esto, en el mismo año aparece un nuevo libro de poemas nerudianos traducido al rumano por Radu Boureanu: se trata de Poeme (Poemas), que reúne de forma bastante heteróclita poemas de varias etapas líricas de Neruda ${ }^{4}$. Hay que observar que este libro, por la selección de los poemas y la deficiente traducción de los mismos, aparece de cierta forma como «desfasado», ya que a finales de 1963, Maria Banuş había ofrecido una buena antología de poemas nerudianos «nuevos» (desde el ciclo de las Odas a Navegaciones y regresos), que indicaban una transformación profunda de la lírica del poeta chileno y que la propia traductora caracteriza como marcado por la «intensificación de las incursiones psicológicas» y por «el tono sarcástico, funambulesco, grotesco, llevado al absurdo con que el poeta juega -en apariencia- con los grandes y los graves temas de la poesía» $(1961,76)$. En otras palabras, la traductora, que por lo demás había también dado en 1956 la versión rumana del poemario con fuertes acentos realistas socialistas de Las uvas y el viento, descubre en esta etapa lírica de Neruda su paso a lo que Hernán Loyola nombró la fase «posmoderna», en que se acusa «la pérdida de aquel sentido de progresión y desarrollo -de marchar hacia una meta deseada- que hasta entonces el Sujeto

4 Una primera sección contiene los primeros 50 sonetos de 100 sonetos de amor (1959) dedicados a Matilde Urrutia. La segunda, titulada «Poeme» (Poemas) comprende (en este orden) «Poema 15» de Veinte poemas de amor y una canción desesperada (1924); un poema escrito cuando Neruda tenía unos dieciseis años, «Un hombre anda bajo la luna» (fechado 1922), no incluido en sus poemarios; el canto introductorio de la cuarta sección de Canto General, "Los libertadores», y del mismo ciclo los poemas «Martí» y «Cuáuhtemoc»; «Explico algunas cosas» de España en el corazón (1936-1937) incluido en Tercera Residencia; el entero poema «Las alturas de Macchu Picchu» de Canto General. Por fin, en la tercera sección se traducen cinco poemas de Canción de gesta (1960). 
había textualizado como una historia de tentativas hacia la producción del autorretrato definitivo, cumplido y satisfactorio» $(1999,29)$. El libro traducido por Banuş en 1963 fue merecedor de cuatro reseñas, una de ella sobresaliente por la fina lectura del ciclo de las Odas en que Şerban Cioculescu vislumbra «el lozano florecimiento de una segunda juventud artística», ya que esta nueva poética combina «la poesía 'pura' y a la vez combativa» y esta es, según el crítico, la dirección seguida por «algunos de nuestros jóvenes poetas más competentes» $(1964,163)$. Si bien esta pretendida conjunción entre la pureza lírica y el carácter combativo es más bien un deseo que una realidad, la mencionada observación de Cioculescu es sugerente en cuanto al influjo que se supone -por lo demás erróneamente- que Neruda pueda ejercitar en la literatura rumana.

En contraste con esta atenta (y actualizada) lectura de Neruda, el tono exaltado del prefacio escrito por Boureanu no puede ocultar cierta superficialidad en la recepción del poeta, que sigue apareciendo aquí bajo la misma imagen "progresista», sin añadir matices nuevos ${ }^{5}$. Además, el desconocimiento del español por parte del traductor lleva a una desmesurada acumulación de errores, cuya ejemplificación sería ociosa. Así, si bien la primera parte del libro contiene poemas de amor y resalta pues aquella faceta de Neruda que prácticamente se había ocultado en las primeras dos décadas del régimen comunista, los poemas escogidos en la segunda parte y la guía de lectura propuesta en el prefacio no contribuyen a ofrecer una ampliación del conocimiento de la poesía de Neruda en Rumania sino más bien a acrecentar, de manera puramente cuantitativa, un tipo de capital simbólico - relacionado con el progresismo y la militanciaque en el escenario cultural rumano empieza a parecer bastante vetusto.

En lo que respecta a la presencia de Neruda en la prensa cultural, desde 1965 las andanzas, percances y triunfos de Neruda, otrora comunicados en detalle a los lectores rumanos, pierden todo interés y, por ejemplo, en 1966, en una «encuesta» titulada «¿Qué saben sobre Rumania?» dirigida a unos diez escritores de desiguales estaturas literarias (desde Graham Greene y Salvatore Quasimodo hasta Elisaveta Bagriana e Ignazio Batutita), a Neruda se le reproduce (sin especificar el contexto y el año) una declaración que se debe suponer que la dio al final de su último viaje a Rumania en 1960, puesto que el poeta chileno afirma, con alusión a su proyecto de 44 poetas rumanos: «Al irme [de este país], me llevo la flor de Rumania: su poesía contemporánea que voy a traducir y publicar para los pueblos de América Latina y España» (Gazeta literară, 1966, 8). Si se considera que en los tiempos pasados en la prensa aparecían incluso notas festivas con la ocasión del aniversario del poeta a sus cincuenta y respectivamente sesenta años, este descuido del antaño encumbrado poeta no puede sino

5 El prefacio termina así: «Con la excepción de los cincuenta sonetos de Cien sonetos de amor, he traducido algunos de aquellos poemas directos, poemas declamados a lo largo y ancho del mundo en pro de la justicia de todos los pueblos, así como su entera obra lleva su mensaje hacia los que deben venir hacia nosotros, hacia el gran número de los hombres conscientes y decididos, que forman el ejército cada vez más numeroso de la paz» (Boureanu, 1965, 11; subrayado nuestro, traducción literal). 
revelar la orientación de la cultura rumana hacia nuevos derroteros y, en particular, hacia un nuevo tipo de escritor representativo para el espacio latinoamericano, en este caso Borges y García Márquez.

Si se exceptúan algunos poemas sueltos (sacados de las Odas y de 100 sonetos de amor y publicados en $1966^{6}$ ), que se pierden entre los muchos artículos y textos relacionados con los escritores del boom, hasta 1970 Neruda casi desaparece del paisaje periodístico rumano. Su nombre se cuela - de una forma que se podría calificar más bien de ignominiosa- en un florilegio titulado «Los poetas del mundo cantan la Revolución [de Octubre]», junto a unos poetas muy menores como Claude Sernet, Genevieve Taggart y David Diopp, con un corto fragmento (más bien un collage de unos 15 versos) de su poema «Meditación sobre la Sierra Maestra - escrito en el año 2000» incluido en Canción de gesta, cuya pésima traducción (firmada por M. Djentemirov, nombre de clara resonancia rusa) y cuya mutilación por el recorte desconsiderado de los versos recuerdan vivamente las poesías publicadas por mero afán propagandístico de finales de los años cuarenta. Por si fuera poco -y como prueba suplementaria de la poca importancia que se da al contenido propiamente dicho cuando de lo que se trata es simplemente de cubrir en una publicación comunista un espacio de pura (y desganada) propaganda obligatoria- Neruda aparece como procedente de ... ¡Cuba! (Neruda, 1966, 6).

Neruda reaparece fulgurantemente en 1970 delante de una multitud de mil chilenos electrizados por su lectura de la poesía de amor de su juventud, en una crónica que cierta viajera rumana por Chile le dedica con la ocasión de la reedición jubilar de 20 poemas de amor y una canción desesperada. En un tono alerta, la crónica hace hincapié en la inmensa popularidad entre los chilenos de Neruda como poeta de amor, alude con una pizca de osadía a la serie de musas inspiradoras y termina con un corto diálogo sobre el amor que, según Neruda, «como el vino y el agua [no necesita] una definición [pues] sirve para sentirlo, hacerlo, perderlo, reencontrarlo, consumirlo, vivirlo, morirlo» (Dumitrescu-Cristian, 1970, 3). La misma viajera publica en un número ulterior de la misma revista Contemporanul la crónica de su visita a la legendaria casa de la Isla Negra y refiere su diálogo con el poeta, que versa principalmente sobre la (necesaria) implicación político-social, el (de nuevo necesario) fortalecimiento de los lazos culturales entre los dos países latinos Chile y Rumania, a cuyo acercamiento Neruda había contribuido por su antología de poesía rumana. Por fin, en la conversación con el poeta se aborda el tema de la capacidad de la poesía de contribuir concretamente a la causa revolucionaria. Se desprende de estas

6 Se trata de «Oda a sus manos», publicada sin traductor mencionado en un períodico oscuro, Săteanca (6 / 1966) y de un «Soneto de amor» traducido por Barbu Socolalu en Viaţa Românească (11 / 1966), dentro de un florilegio titulado «Los poetas del mundo», donde se traducen versos -entre otros- de Saint-John Perse, Paul Celan, Eugenio Montale, Emily Dickinson. 
dos crónicas, cuya relativa frivolidad reflejan bastante bien el clima de la Rumania del «deshielo cultural», un instantáneo de la figura de Neruda que más llamaba la atención en esta época y en este país: el poeta del amor, por un lado, y el promotor de la cultura rumana en el mundo, a través de la antología 44 poetas rumanos, por otro lado.

\section{$1971-1989$}

A diferencia de la mayoría de los países del bloque socialista, donde la liberalización fue avanzando sin grandes tropiezos hasta la caída del muro de Berlín, en Rumania tiene lugar en 1971 una así llamada «minirrevolución cultural» (Cătănuş, 2005), inspirada en el modelo asiático con el cual Ceauşescu tomó contacto a principios del mismo año, cuando visitó la República Popular China y Corea del Norte. El culto a la personalidad y la orientación nacionalista que mejor se patentiza en el «protocronismo» rumano (o sea, la pretendida anticipación a nivel nacional de todos los grandes logros de la humanidad ${ }^{7}$ ) van a infestar como una plaga las revistas rumanas hasta la Revolución anticomunista de 1989 y el escenario cultural cobrará un aspecto escindido en cuatro frentes más o menos netos: los oportunistas (cultores de la pareja presidencial y autores de textos bombásticos de -insincera- adhesión partidista), los subversivos (especialistas en el arte de esquivar la censura, maestros de la alusión y del doble sentido), los disidentes (inadaptados, marginados, exiliados) y los evasionistas (experimentalistas practicantes de un esteticismo en principio apolítico) (Simuţ, 2017).

En este contexto transformado, la figura de Neruda conocerá un destino bastante interesante, puesto que, si hasta 1964 su poesía fue confiscada por los gatekeepers reaccionarios y dogmáticos y convertida en un ejemplo de lírica "ortodoxa», en cambio en el tramo final de la dictadura comunista, se asiste a una doble recepción, porque a su faceta militante comunista ejemplar, que será literalmente empleada por los oportunistas en los florilegios de lírica propagandística, se le opone aquella imagen de gran poeta de talla mundial, que unos hispanistas rumanos honestos y sensibles procurarán poner de relieve y rescatar de la desmesurada acumulación de estereotipos ideológicos vertidos sobre su figura.

En 1971, cuando Neruda recibe el Nobel, se da un relativo aumento de la presencia del poeta chileno en la prensa rumana, pero al fin y al cabo este acontecimiento está señalado con una parquedad que más bien tiene visos de cortesía que de verdadero interés. Solo en la principal revista de la Unión de Escritores de Rumania, România literară (sucesora, desde 1969, de Gazeta literară) se le concede un espacio más amplio: aquí aparece una página de versos retomados de varios libros de Neruda publicados en

7 Ver al respecto el capítulo 5 titulado «Romanian Protochronism» del libro de Katherine Verdery (1991). 
distintas épocas por traductores como Jebeleanu, Boureanu, Banuş y Aurel Covaci. Se traduce también una entrevista de L’Express titulada «¿Quién es Ud., Pablo Neruda?» y el respetable crítico literario Nicolae Balotă escribe un bello ensayo sobre Neruda, donde pasa revista de las diversas etapas de su creación, hace hincapié en la comunidad fraterna que formó en la España de la Guerra Civil con Lorca, Miguel Hernández, Rafael Alberti y también refiere su ilustre descendencia de «Baudelaire, Rimbaud, Rubén Darío, Walt Whitman, Maiakovski», siendo especialmente los últimos dos «sus modelos ejemplares, por su exuberancia, sinceridad, anticonvencionalismo» (1971, 16). Es este el único texto que homenajea al nobel de 1971, porque en otras tres revistas -Steaua, Viaţa Românească y Familia- el altísimo galardón ofrecido a Neruda está saludado con meras y parcas selecciones de poemas retomados de diversas etapas de su creación.

Ya que las ausencias son también significativas, es digno de destacar que Neruda no figura en una vasta antología de unas 900 páginas titulada Panorama poeziei universale contemporane (Panorama de la poesía universal contemporánea) elaborada por A.E. Baconsky en que el poeta, crítico y traductor de Cluj incluye solo a los poetas que considera fundamentales para ilustrar la dicción única de la poesía de la primera mitad del siglo XX, o sea del High Modernism. Incluye «solo a los poetas y no a los profesores de poesía», cuyo prototipo sería Valéry (1972, 17, subrayado en original) y tampoco a los «teóricos de las corrientes poéticas de esa época» como Tzara o Breton (18), así como también omite a los poetas que le producen una «aversión estructural» como un Saint-John Perse, por ejemplo. La exclusión de «esta águila de los Andes, Pablo Neruda» se explica así: "perdón, sus frases dilatadas, incluido su material metafórico de aluvión impresionante, nunca me han dicho gran cosa» (17). Entre los compatriotas de Neruda, Baconsky no omite sin embargo a Gabriela Mistral y a Vicente Huidobro, admirado sin reservas, así como no omite a uno de los poetas que más corresponden a su ideal de poesía moderna auténtica y a quien, de hecho, había introducido en la cultura rumana en 1960, César Vallejo.

Como mencionamos, en estos años los rumanos estaban en pleno proceso de descubrimiento del boom latinoamericano y, con él, de toda la prosa que lo había posibilitado: ya desde mediados de los 1960 aparecen en las revistas culturales (y especialmente en Secolul 20) cuentos, novelas cortas, amplios fragmentos de novelas de los «nuevos» escritores latinoamericanos; en 1969 se publicó una antología titulada Sfîrşitul jocului (Final del juego) que comprendía una gran parte de los cuentos (muy bien traducidos) de Julio Cortázar y en el mismo año apareció La muerte de Artemio Cruz de Carlos Fuentes; en 1970 se traduce (logradamente) La casa verde de Mario Vargas Llosa; en 1971 se publicó la versión rumana (bastante imperfecta) de Cien años de soledad de García Márquez, firmada por Mihnea Gheorghiu (un anglista que trabajó con «negros» para esta edición); en 1972 aparece la traducción (harto deficiente) de una 
antología de las prosas más importantes de Borges elaborada por Darie Novăceanu ${ }^{8}$. Las revistas rumanas dedican amplios espacios que registran la conmoción producida entre los rumanos por esta literatura que, además de su valor estético incuestionable, también produce el gratificante sentimiento de estar conectado con la actualidad más álgida de Occidente, en cuyos países se traducían a los escritores relacionados con el boom más o menos por los mismos años. Ante el deslumbramiento provocado por estos prosistas geniales, el nombre de Neruda tiene mucho menos que decir a los rumanos que descubren la Latinoamérica literaria dentro de un horizonte de expectativas totalmente transformado y especialmente bajo el ángulo de su narrativa. Es digna de señalar, no obstante, la tentativa del hispanista Darie Novăceanu de aprovechar esta afortunada coyuntura para llamar la atención también sobre la poesía de este espacio, introduciendo su «microantología» de poesía latinoamericana publicada en România literară en 1973 con una llamada de atención sobre el hecho de que «América Latina, un mundo cada vez más cercano y conocido por nosotros [los rumanos], ha tenido siempre una poesía de una belleza sin par y hoy [...] las generaciones nuevas le dan un nuevo brillo» $(1973,28)$. No obstante, estas «generaciones nuevas» son más bien de edad variada, ya que en este florilegio figuran, entre otros, Huidobro, Borges, Macedonio Fernández, Cisneros, Nicolás Guillén, Jamís Fayad y Neruda con su poema «Los poetas celestes» de Canto general.

En 1973 se publica un último libro de poesías de Neruda, titulado Mătasea şi metalul (La seda y el metal) que representa de hecho la traducción integral de Los versos del capitán. La atípica historia de este libro está sugerida (sin nombrarse claramente el «conflicto») en la cortísima presentación con la cual el excelente traductor Aurel Covaci acompaña su traducción: este libro fue publicado inicialmente en Nápoles, como supuesta obra póstuma de un héroe desconocido, con una carta al editor dirigida por la destinataria de los versos, nombrada Rosario de la Cerda. No se especifica en cambio que estos versos son los que Neruda escribía durante su viaje por la URSS y los países comunistas, a escondidas de su mujer de aquel entonces, Delia del Carril (Feinstein, 2004, 335-6) y que el poeta recurrió a la estratagema de publicarlos como un manuscrito encontrado para ocultar su identidad y no herir excesivamente a Delia. Escrito pues a la par que Las uvas y el viento, el libro representa la faceta sentimental del

8 Merece señalarse que esta abundancia de títulos de literatura latinoamericana surge sobre el fondo de una escasez de literatura extranjera traducida, ya que la crisis económica en que empieza a hundirse el país y que redunda en la dificultad de pagar los derechos de autor conduce a un descenso significativo del número de las novelas occidentales traducidas (francesas, inglesas, norteamericanas, etc.). Observa un investigador de la producción cuantitativa de las novelas traducidas al rumano: «As apart from the rendition of authors such Jorge Amado produced in the 1950s, the translations of Latin American novels published in the 1970s, the revival of aesthetic interest in writers such as Vargas Llosa, Cortázar, Márquez and Sabato, and the renditions of American works such as Vonnegut's and Gore Vidal's are but exception to the rule. In 1984, for example, almost all Romanian translations of French literature are reprints of already translated French novels. The previous decade's Western rush was substituted, in literary debates, by a fascination with Latin American literature» (Baghiu, 2018, 79). 
poeta que justo en los mismos meses escribía una poesía militante dedicada al socialismo de la URSS y sus satélites. De esta forma, los lectores rumanos tienen la ocasión de conocer las dos caras de Neruda a principios de la década de los cincuenta -poeta político y poeta del amor-. La revelación sucesiva de estas dos caras, por la traducción de Las uvas y el viento en 1956 y de Los versos del capitán en 1973, arroja una clara luz sobre las trazas del tipo de oferta cultural que se concibe apropiada para el público rumano a finales del «estalinismo integral», por una parte, y después del «deshielo cultural», por otra parte.

De hecho, la muerte de Neruda en el mismo año 1973 le da de nuevo mayor visibilidad al poeta chileno a quien se le dedican unos cuatro obituarios de varias dimensiones, en general acompañados de versos seleccionados de su última etapa de creación. Esta etapa parece ser la que más atrae a los intelectuales «evasionistas» apolíticos (en la terminología de Simuţ), o sea los que seguían practicando y difundiendo una literatura considerada únicamente bajo el ángulo estético, sin contaminaciones ideológicas. Entre los escritores que lo homenajean, Mihai Beniuc, que se considera su cercano amigo por haberlo acompañado en las tres visitas en Rumania, le dedica una elegía publicada en România literară, y su traductora Maria Banuş manifiesta con sinceridad su conmoción ante la terrible noticia de su fallecimiento. Un artículo también publicado en 1973 recalca su insigne papel como difusor de la poesía rumana en el espacio hispánico por la antología 44 poetas rumanos «que llega a unos niveles inalcanzables hasta ahora por ninguna de las obras dedicadas en el extranjero a la literatura rumana» (N., 1973, 31). En la época de alza del nacionalismo, una empresa de este tipo -que, por otra parte, varios estudiosos consideran más bien deficiente desde el punto de vista de la traducción (ver Capraroiu, 2007, 15)- halagaba el orgullo de los dirigentes de la cultura rumana y añadía un nuevo motivo de admiración por el gran poeta chileno. Por otra parte, la muerte del poeta está sobria y adecuadamente lamentada por el insigne hispanista rumano Andrei Ionescu que marca el triste acontecimiento por la traducción de dos poemas del último poemario de Neruda publicado en vida, Geografía infructuosa (1972), acompañada de una nota en que reproduce la justificación que el propio poeta aducía ante los críticos de su constante (¡exagerado!) compromiso político: «Tengo un pacto de amor con la hermosura: / tengo un pacto de sangre con mi pueblo» (Neruda, 2004, 13; Ionescu, 1973, 31).

De hecho, a un año de su muerte, el mismo hispanista acompañado por Victor Ivanovici le dedica en la revista Secolul 20 un espacio consistente a Neruda, con una cuantiosa selección de los poemas póstumos publicados en La rosa separada (1973), El mar y las campanas (1973), Jardín de invierno (1974) y El libro de las preguntas (1974), un amplio fragmento de Confieso que he vivido. Se añade un dossier con testimonios sobre los últimos días del poeta, ensombrecidos por los humillantes actos de brutalidad cometidos contra el poeta enfermo por los policías de Pinochet, así como se publica un 
florilegio de textos escritos por unos admiradores y allegados amigos como Rafael Alberti, Iannis Ritsos, Eugen Jebeleanu, Omar Lara, etc. También en la revista Steaua - en general reticente en promocionar su poesía- se publican en el mismo año y con el mismo triste motivo tres poemas póstumos ${ }^{9}$, que, como se ve, son los que más llaman la atención de los intelectuales «apolíticos» (estetas) de mediados de los años 1970.

A partir de su paso a la etapa póstuma, Neruda empieza a recobrar cierto relieve en la prensa rumana. Dos amplios fragmentos de Confieso que he vivido se publican en sendas revistas (România literară y Luceafărul) en 1975, cuando también aparecen, en la traducción de su fiel traductora y amiga Maria Banuş, «Explico algunas cosas» de España en el corazón y, en Steaua, la poesía «A Siqueiros, al partir», como ilustración de un corto ensayo dedicado al pintor mexicano. Neruda va a figurar casi cada año, hasta 1989, con al menos un poema integrado en florilegios de poesía chilena o latinoamericana (junto a Gabriela Mistral, Vicente Huidobro, Braulio Arenas, pero también en la compañía de Borges, Cortázar o Gonzalo Rojas) ${ }^{10}$, en cambio las microantologías publicadas en la prensa que comprendan únicamente poesías nerudianas desaparecerán, con dos notables excepciones, que comentaremos brevemente.

A cinco años de su muerte, un nuevo homenaje le rinde su compatriota Omar Lara, afincado en estos años en Rumania donde se desempeña como un admirable traductor y agente cultural entre los espacios de origen y de adopción. En una amplia página de Luceafărul Lara presenta una faceta menos conocida de Neruda, la de ensayista, traduciendo un fragmento de ensayo dedicado a Quevedo, y da unas versiones propias de versos pertenecientes a varias etapas nerudianas - desde «Alturas de Macchu Picchu» y Las uvas y el viento hasta «El libro de las preguntas»-. En el texto que acompaña esta selección de versos y prosa Lara indica claramente el lugar central de Neruda en el panorama lírico latinoamericano, al lado de Huidobro, Mistral y Vallejo, y apunta, con plena razón, que «todos los poetas posteriores a él [hicieron] su aprendizaje con Neruda. Si bien lo hicieron por oposición o por negación» $(1978,8)$.

Se debe de hecho observar que la relativa discreción de la figura de Neruda en la prensa cultural de los años 1970 y 1980, tan contrastante con la estrepitosa promoción que se le hacía en las primeras dos décadas del régimen comunista, le sienta mucho mejor al poeta. Su estatura poética está puesta en evidencia de forma más reflexiva y argumentada en los pocos, pero juiciosos estudios u homenajes que se le brindan y así,

9 Los poemas XXVII, VII (Los hombres) de 2000 (1974) y «Jardín de invierno» del libro con el mismo título (1974).

10 Se trata de las microantologías publicadas en: Tribuna (6/1975), donde aparece -entre otros- junto a Borges, Gabriela Mistral, Nicolás Guillén, con su poema «Patagonia»; Cronica (18 / 1976), al lado de Vicente Aleixandre e Yvan Goll, con «La bandera» de Canto general; Luceafărul (35 / 1977), en un florilegio titulado sugerentemente «De la lírica antifascista», donde figura con la «Oda al alambre de púas" junto a 12 poetas de nacionalidades diferentes; Luceafărul (37 / 1977) donde Omar Lara antologiza y traduce un florilegio titulado «Poetas chilenos», en que Neruda figura con «Preguntas» al lado de Carlos Pezoa Veliz, Gabriela Mistral, Enrique Lihn, Armando Uribe Arce y Jorge Teiller. 
por ejemplo, Paul Alexandru Georgescu vuelve a dedicarle un artículo en 1978 titulado «Pablo Neruda y los devenires poéticos», que también incluirá un año más tarde en su libro Literatura hispanoamericana en perspectiva sistémica con el sugerente título «Una gran voz poética del mundo: Pablo Neruda». En este texto, tras un breve repaso de sus varias etapas de creación, Georgescu insiste en la decantación de su poesía al final de su trayectoria:

El supremo personaje nerudiano es el poeta otoñal de Cien poemas de amor y Memorial de la Isla Negra. En estas, el poeta pasa de la vehemencia vital a la gravedad meditativa, de la certeza apodíctica a la pregunta y la duda que abren la vía de las verdades profundas de la imaginación ejemplar. La poesía del otoño significa asimismo la transfiguración y el ennoblecimiento de los temas fundamentes de las fases anteriores: el amor adquiere la reverberación de la adoración absoluta, el dolor se convierte en fuente de dignidad y esperanza, el compromiso político e ideológico, interiorizado y amoldado al destino humano, adquiere el patetismo del drama humano. $(1978,42)$

En 1982 aparece la traducción de las memorias de Neruda, Confieso que he vivido, reseñada con atención en dos publicaciones y de nuevo se puede comprobar el tono ponderado, sin duda admirativo, pero encaminado más bien a sopesar el valor literario de este libro en vez de formular panegíricos exaltados. Paul Alexandru Georgescu se propone leer estas memorias como una invitación de pasar del «conocimiento 'perceptivo' de la vida» a un "conocimiento 'meditativo' de la creación nerudiana», concluyendo: «Los que buscarán en Confieso que he vivido claves para un mejor entendimiento de la obra de Neruda [...] encontrarán asimismo un hilo de Ariadna para no perderse en una obra asombrosamente vasta, proteica, multifacética» $(1982,10)$.

En la esquizofrenia galopante que desde finales de los setenta hasta 1989 aflige la cultura rumana sometida a un doble discurso -el de la rimbombancia propagandística, cada vez más estridente pero también más hueca, y el del acto intelectual auténtico-, Pablo Neruda volverá a ser «empleado» por los oportunistas para figurar en diversos florilegios de poesía comprometida, y asimismo sus poemas «Los dioses del río» y «La boca que canta», dedicados a Rumania, de Las uvas y el viento se reproducirán con frecuencia en las microantologías (cada vez más numerosas) tituladas «Los poetas del mundo cantan a Rumania», que evidencian el giro nacionalista de las políticas culturales ceausistas ${ }^{11}$.

11 Estos florilegios oportunistas se multiplican especialmente a partir de 1979 y casi siempre Neruda está acompañado por otro nobel latinoamericano "gran amigo de Rumania», Miguel Ángel Asturias. En România literară (34 / 1979) Asturias figura con un fragmento de «Vergel de suelo de oro» y Neruda con «Ahora canta el Danubio» y «Los dioses del río»; en Luceafărul (29 / 1980), en el florilegio «Palabra sobre Rumania», se publican «Los estandartes de Rumania» de Asturias y Neruda aparece con 
Por otra parte, el mismo poeta aparece en la prensa cultural con poemas más profundos, de diversas etapas, destacándose un florilegio de 1980, donde Omar Lara reúne diversos fragmentos líricos atravesados por el tema (¡tan poco «comunista»!) de la muerte, entre estos el conocido poema «Walking Around» de Residencia en la tierra, estimado por algunos críticos como el más pesimista poema en lengua española ( $\mathrm{Fe}$ instein, 2005, 121) ${ }^{12}$. De hecho, en este último (negro) período del régimen comunista, es este poeta y traductor chileno quien se encargará, por sus retraducciones de poemas ya publicados anteriormente y por las traducciones de poemas todavía desconocidos, de no dejar caer en el olvido a su admirado compatriota y de evidenciar la multiplicidad y complejidad de las facetas de Neruda ${ }^{13}$. Con ello, este último gatekeeper de Neruda en Rumania pretende desocultar la grandeza del poeta chileno, que prácticamente había sido oscurecida, sobre todo antes de 1964, por el aluvión de elogios que se le dirigieron con el fin de convertirlo en un perfecto aliado de las políticas culturales comunistas y de erigir su poesía en un modelo ejemplar de lírica socialista.

\section{Conclusiones}

Entre 1965 y 1973, año de su muerte, la poesía de Neruda conoce una serie de transformaciones que, en gran medida, son el reflejo de una reconsideración de su ideología marxista y de su posicionamiento como militante comunista capaz, entre otras, de excusar los excesivos rigores del régimen estaliniano en pro de construir una sociedad considerada más justa y humana gracias al socialismo. El informe de Jruschov en el XX Congreso del Partido Comunista de la Unión Soviética (1956) que denunció el autoritarismo estaliniano produjo también en Neruda una conmoción que redundó en una «desestalinización» de su propio proceso creativo (Pedemonte, 2015, 176). Su enorme entusiasmo provocado por la Revolución cubana estuvo no obstante mitigado por la desconfianza que le provocaba el potencial autoritarismo de Fidel Castro (Edwards, 1990; Piqueras Flores, 2014; Pedemonte, 2015) y ulteriormente ensombrecido

la misma «Ahora canta el Danubio» y los poemas «A mi partido» y «Volveré»; en Tribuna (33 / 1983), entre los cinco «Poetas del mundo [que] cantan a Rumania» figura Asturias con «La misma imagen» $y$ Neruda con «La boca que canta»; el mismo poema se publica en Tomis (16 / 1981), Ramuri (7 / 1984), Contemporanul (34 / 1988), Tribuna (12/1989).

12 El florilegio contiene, además de «Walking Around» de Residencia en la tierra, que Loyola $(1999,27)$ considera «el nadir del temple moral del Sujeto residenciario», los poemas «Ausencia de Joaquín», «Unidad», «Entierro en el este» del mismo libro, «Si cada día cae» $\mathrm{y}$ "Gracias, violines» de El mar y las campanas (1974) y los poemas XXII y LXII de Elegía (1974).

13 Se debe no obstante mencionar que Omar Lara, que también publica en un número de România literară (29 / 1979) «Ritual de mis piernas» de Residencia en la tierra - no es el único traductor que rescata la faceta meditativa y pesimista de Neruda: en Convorbiri literare (10/1981) Dana Diaconu compone una microantología de poesía latinoamericana que incluye, entre otros, poemas de Octavio Paz («Seven P.M. »), César Vallejo («Masa») así como «Unidad» y «Entierro en el este» (de Residencia en la tierra) de Neruda-. Por su lado, Ana Maria Moldovan, en Familia (7 / 1981) traduce «Estación inmóvil» de Navegaciones y regresos, «Barcarola» (del libro homónimo de 1967) y «Vuelve el otoño» (de Residencia en la tierra). 
por la carta que le dirigieron una larga lista de escritores cubanos para reprocharle su participación en la reunión de Pen Club celebrada en Nueva York en 1966. La invasión de las tropas soviéticas y sus aliadas del bloque socialista (con la notable excepción de Rumania) en la primavera de Praga de 1968 también dejó una huella amarga en la conciencia de Neruda, obligándole a replantearse sus convicciones íntimas. De hecho, ya desde Estravagario (1958) se observa una mutación importante en su producción lírica que, según Hernán Loyola, entra en una fase "posmoderna» en la cual «el Sujeto (enunciador y protagonista del discurso) nerudiano [deja] de proponerse metas u horizontes» $(1999,29)$, para que, en los libros postreros de Neruda se consuma «el final reajuste de las antiguas pretensiones oraculares del Sujeto moderno -la superior voz 'profética'- y la reaceptación de una humanidad compartida» (30).

En la cultura rumana la figura de Neruda, construida en las primeras décadas del régimen comunista como encarnación del poeta-vate que dirige los pueblos hacia el luminoso futuro comunista, sufre también unas modificaciones importantes, si bien ellas reflejan solo en parte las profundas transformaciones interiores del poeta chileno. No obstante, se puede observar que sobre todo en los años del «deshielo cultural» plenario (hasta 1971) la imagen de Neruda se despoja de la avalancha de estereotipos ideológicos que, al fin y al cabo, habían llegado a empañar la recepción de su vigorosa y original poesía. Los críticos encaminados a promover una literatura de factura exclusivamente estética resaltan elogiosamente su poética minimalista del ciclo de las Odas, así como ponderan con admiración su (nueva) poesía amorosa. La poesía de su última militancia a favor de la causa cubana, tan vehiculada en los primeros años de 1960, figura únicamente en el último libro de Neruda publicado en Rumania bajo la égida del "progresismo» (nos referimos a Poezii traducido por Radu Boureanu en 1965), pero desaparece de la prensa cultural. No obstante, en medio del mismo «deshielo cultural», en 1967, se publica la antología 44 poetas rumanos en la editorial Losada de Buenos Aires, la cual le dará al poeta chileno una nueva imagen en la cultura rumana -por lo demás (pero entendiblemente) sobreestimada en relación con la importancia real que tiene este proyecto en la actividad creadora del poeta-. Esta faz de «gran amigo de Rumania» será asiduamente promovida por los dirigentes de las políticas culturales desde finales de los años 1970 y sobre todo en la década de los 1980, cuando el nacionalismo, inseparable del cada vez más desorbitado culto a Ceauşescu, afligirá tristemente la cultura rumana. Resulta realmente penoso observar cómo se reciclan los versos dedicados a Rumania de Las uvas y el viento, sobre todo en la segunda mitad de los años 1980, que, casi siempre, vienen acompañados por los versos (igualmente ajados) de Miguel Ángel Asturias, presentado también como otro «gran amigo de Rumania». Los dos premios nobel latinoamericanos que se inclinan hacia la grandeza del socialismo rumano no podían sino halagar el orgullo cada vez más hinchado de la pareja presidencial y de sus secuaces oportunistas. 
Afortunadamente, el Pablo Neruda del último período de su vida y de su creación recibe también un reconocimiento sincero y esta vez no agraviado por ninguna imposición política entre los intelectuales rumanos que publican extensas selecciones -y precisamente en Secolul 20 y en Steaua, es decir las revistas más alejadas del predio periodístico de los oportunistas - de su poesía póstuma, de factura posmoderna. Se destaca también la labor de Omar Lara, el último gatekeeper de Neruda en el período socialista, que se esmera en desocultar también los tesoros escondidos en la primera etapa de creación de su admirado compatriota, correspondiente a Residencia en la tierra, apuntando así a una deseada completitud de la imagen de Neruda en Rumania.

\section{Bibliografía}

Baconsky, A. E., Panorama poeziei universale contemporane, Bucureşti 1972.

Baghiu, Şt., Strong Domination and Subtle Dispersion: A Distant Reading of Novel Translation in Communist Romania (1944-1989), en: The Culture of Translation in Romania / Übersezungskultur und Literatursetzen in Rumänien (eds. Sass, M.; Baghiu, Şt.; Pojoga, V.), Berlin 2018.

Balotă, N., Pablo Neruda, România literară 44, 1971, pp. 16.

Banuş, M., Accente inedite în poezia lui Pablo Neruda, Secolul 20 5, 1961, pp. 73-79.

Capraroiu, G., La conexión rumana: Alberti, Neruda, Lara, Los Angeles 2007 (Tesis doctoral, University of California).

Cătănuș, A.-M., Sfârșitul perioadei liberale a regimului Ceaușescu: minirevoluția culturală din 1971, Bucureşti 2005.

Cioculescu, Ș., Pablo Neruda în româneşte, Secolul 20 9, 1964, pp. 159-165.

Dumitrescu-Cristian, S., Pablo Neruda: 20 de poeme de dragoste şi un cîntec de disperare, Contemporanul 31, 1970, p. 3.

Edwards, J., Adiós, poeta ..., Barcelona 1990.

Feinstein, A., Pablo Neruda: A Passion for Life, New York / London 2004.

Georgescu, P. A., Neruda şi devenirile poetice, Steaua 9, 1978, pp. 41-42.

Georgescu, P. A., O mare voce poetică a lumii: Pablo Neruda, en: Literatura hispano-americană în lumină sistemică, Craiova 1979, pp. 245-249.

Georgescu, P. A., Memoriile lui Neruda, Tribuna 24, 1982, p. 10.

Ilian, I., Latinoamérica en la prensa cultural rumana: 1959-1965. La historia de una instrumentalización política de la literatura (en prensa).

Ilian, I., Țiței, A., La poesía latinoamericana traducida en la Rumania socialista (19451964) (en prensa).

Ionescu, A., Pablo Neruda, România literară 39, 1973, p. 31.

Lara, O., Pablo Neruda, Luceafărul 38/858, 1978, p. 8. 
Locane, J., Literatura comunista mundial, en: World Editors. Dynamics of Global Publishing and the Latin American Case between the Archive and the Digital Age (eds. Guerrero, G.; Loy, B.; Müller, G.), Berlin 2021, pp. 191-207, https://doi. org/10.1515/9783110713015-013.

Loyola, H., Neruda moderno / Neruda posmoderno, América sin nombre 1, 1999, pp. 21-32.

Marling, W., Gatekeepers: the Emergence of World Literature and the 1960s, New York 2016.

N., N., Editura argentiniană Losada şi literatura română, România literară 38, 1973, p. 31.

Negrici, E., Literatura română sub comunism, Iaşi 2019.

Neruda, P., Cîntec din anul 2000 (trad. M. Djentemirov), Luceafărul 43, 1966, p. 6.

Neruda, P., Canción de gesta. Las piedras de Chile, Buenos Aires 2004.

Novăceanu, D., Din poezia Americii Latine, România literară 34, 1973, pp. 28-30.

Pedemonte Lavis, R., Pablo Neruda, su tiempo y el «sentido de la historia»: postura ideológica y creación poética durante la Guerra Fría, Ayer 98/2, 2015, pp. 159-185.

Piqueras Flores, M., ¿Era tan limpia la rosa del Caribe? Neruda y la Revolución cubana a la luz de Confieso que he vivido y sus silencios, Revista Historia Autónoma 6, 2015, pp. 75-84.

Simuţ, I., Literaturile române postbelice, Cluj-Napoca 2017.

${ }^{* * \star}$ Ce știți despre România?, Gazeta literară 33, 1966, p. 8.

\section{Libros de Neruda publicados en la Rumania del período socialista:}

Neruda, Pablo (1948). Să se trezească pădurarul. Bucureşti: Editura Partidului Muncitoresc Romîn. Traducción de George Demetru Pan. Con una introducción del traductor. [Que despierte el leñador]

Neruda, Pablo (1950). Poeme. Bucureşti: Editura de Stat. Traducción de George Varta. Introducción de Ilya Ehrenburg. [Poemas extraídos de Tercera Residencia y Canto General, con una nueva traducción de Que despierte el leñador]

Neruda, Pablo (1951). Poeme. Bucureşti: Editura de Stat pentru Literatură şi Artă. Traducción de Eugen Jebeleanu. [Poemas de «Coral de año nuevo para la patria en tinieblas» $\mathrm{y}$ «Recabarren» de Canto general, a los cuales se añaden los poemas dedicados por Neruda a China, que iban a figurar en Las uvas y el viento]

Neruda, Pablo (1956). Strugurii şi vîntul. București: Editura de Stat pentru Literatură şi Artă. Traducción de Maria Banuş. Con una introducción de la traductora. [Las uvas y el viento]

Neruda, Pablo (1963). Poezii noi. Bucureşti: Editura pentru Literatură Universală. Traducción de Maria Banuș. [Poemas de Odas elementales, Nuevas odas elementales, Tercer libro de las odas, Estravagario, Navegaciones y regresos] 
Neruda, Pablo (1965). Poeme. Bucureşti: Editura Tineretului. Traducción de Radu Boureanu. Con una introducción del traductor. [50 sonetos de Cien sonetos de amor, una selección de Veinte poemas de amor y una canción desesperada, Canto General, Tercera Residencia y Canción de gesta].

Neruda, Pablo (1973). Mătasea şi metalul. Bucureşti: Editura Univers. Traducción de Aurel Covaci. [Los versos del capitán]

Neruda, Pablo (1982). Mărturisesc că am trăit. Bucureşti: Editura Politică. Traducción de Nina Ecaterina Popescu. Con una introducción de Eugen Jebeleanu. [Confieso que he vivido]

\section{La(s) figura(s) de Pablo Neruda construida(s) en la cultura rumana de la segunda etapa del régimen comunista rumano (1965-1989)}

Palabras clave: Pablo Neruda, régimen comunista rumano, tensiones del campo cultural, recepción literaria, traducción

Nos proponemos en este artículo presentar el proceso por el cual se remodela la imagen de Neruda en la segunda etapa del régimen comunista rumano (1965-1989), después de su desmesurado ensalzamiento entre 1947 y 1964 en calidad de ejemplar «compañero de ruta» en la construcción del socialismo. Confiscada inicialmente por unos agentes culturales y traductores aferrados a los dogmas del realismo socialista, su valiosa poesía consigue ocupar su merecido lugar durante «el deshielo cultural» e incluso después de 1971, cuando las políticas culturales ceausistas se orientaron hacia un nuevo dogmatismo de factura nacionalista. Si bien, en comparación con las primeras dos décadas del totalitarismo, su visibilidad decrece y su figura se esfuma entre los nuevos latinoamericanos llegados al escenario cultural rumano - los autores del boom -, la poesía de Neruda sigue presente en Rumania y ella será tanto instrumentalizada por los oportunistas del aparato de propaganda ceausista-nacionalista como rescatada de los clisés ideológicos por los agentes culturales del frente apolítico, estetizante. 


\section{Podoba/-e Pabla Nerude v romunski kulturi v drugi etapi romunskega komunističnega režima (1965-1989)}

Ključne besede: Pablo Neruda, romunski komunistični režim, napetosti na kulturnem področju, literarna recepcija, prevajanje

Članek predstavlja proces, v katerem se je preoblikovala Nerudova podoba v drugi etapi romunskega komunističnega režima (1965-1989), po pretiranem poveličevanju med letoma 1947 in 1964 v vlogi »popotnega tovariša « pri izgradnji socializma. Njegova poezija, ki so se je sprva polastili kulturni agenti in prevajalci, privrženci dogem socialističnega realizma, je v obdobju »kulturne otoplitve« in po letu 1971, ko so se kulturne politike Ceauşescove linije usmerile proti novemu, nacionalistično obarvanemu dogmatizmu, zasedla zasluženo mesto. Čeprav se je v primerjavi s prvima totalitarističnima desetletjema pesnikova prepoznavnost zmanjšala in njegova podoba zabrisala med novimi Latinoameričani, ki so stopili na romunsko kulturno prizorišče - avtorji booma -, se je njegova poezija v Romuniji obdržala in so jo na eni strani izrabljali oportunisti Ceauşescovega nacionalističnega propagandnega aparata, na drugi pa so jo kulturni agenti iz apolitičnega, esteticističnega tabora reševali ideoloških klišejev.

\section{The Image(s) of Pablo Neruda Constructed in Romanian Culture during the Second Phase of the Romanian Communist Regime (1965-1989)}

Keywords: Pablo Neruda, Romanian Communist Regime, cultural field tensions, literary reception, translation

In this article we explore the process by which Neruda's image was reshaped in the second phase of the Romanian communist regime (1965-1989), following the first phase between 1947 and 1964 during which he was held up in adulation as an exemplary "road companion" in the construction of socialism. After initially being hijacked by cultural actors and translators who clung to the dogma of socialist realism, his poetry then came to occupy its rightful place during "the cultural thaw" and even after 1971, when Ceaușescu's cultural policies took a new nationalist turn. Although, compared to the first two decades of totalitarianism, his visibility decreased with the new wave of Latin Americans writers arriving on the Romanian cultural scene, notably the Latin American Boom authors, Neruda's poetry still had a presence in Romania and was 
at once instrumentalized by the opportunists who jumped on the bandwagon of the Ceaușescu's nationalist propaganda apparatus and rescued from the ideological clichés by the cultural actors of the new apolitical, aestheticizing movement.

\section{O avtorici}

Ilinca Ilian je izredna profesorica na Oddelku za hispanistične študije Filozofske fakultete Zahodne univerze $\mathrm{v}$ Temišvaru, predavala je tudi na univerzah v Mehiki (UANL, Monterrey) in Franciji (Univerza Paula Valéryja v Montpellieru in EHESS, Pariz). Je ustanoviteljica in koordinatorica Regionalne mreže hispanistov srednje in jugovzhodne Evrope in glavna urednica revije Colindancias. Objavila je veliko člankov in knjig o latinskoameriški književnosti 20. stoletja (npr. Julio Cortázar y Robert Musil - consonancias, divergencias y ecos) in njeni recepciji v Romuniji. Njeni najpomembnejši literarni prevodi so Rayuela (Ristanc) Julia Cortázarja, Altazor Vicenta Huidobra in El beso de la mujer araña (Poljub ženske pajka) Manuela Puiga.

E-naslov: ilincasn@gmail.com

\section{Abouth the author}

Ilinca Ilian is an associate professor at the Department of Hispanic Studies at the Faculty of Arts, West University of Timisoara. She has also lectured at universities in Mexico (UANL, Monterrey), in France (Paul Valery University of Montpelier). She is the co-founder and coordinator of the regional network of Hispanic Studies scholars in Central and Southeast Europe and chief editor of the journal Colindancias. She has published numerous articles and books on $20^{\text {th }}$ century Latin American literature including Julio Cortázar y Robert Musil - consonancias, divergencias y ecos and its reception in Romania. She is also a literary translator and has translated, amongst other works, Julio Cortázar's Rayuela ("Hopscotch"), Vicente Huidobro's Altazor and Manuel Puig's El beso de la mujer araña ("Kiss of the Spider Woman").

E-mail: ilincasn@gmail.com 